\title{
Polyarticular juvenile idiopathic arthritis - epidemiology and management approaches
}

This article was published in the following Dove Press journal:

Clinical Epidemiology

24 October 2014

Number of times this article has been viewed

\section{Edward J Oberle \\ Julia G Harris \\ James W Verbsky}

Department of Pediatrics, Division of Rheumatology, Medical College of Wisconsin, Milwaukee, WI, USA
Correspondence: James W Verbsky Children's Hospital of Wisconsin, Medical College of Wisconsin, Suite 465, 9000 W Wisconsin Ave, Milwaukee, WI 53226, USA

$\mathrm{Tel}+\mathrm{I} 414266670$ I

Fax + I $4 \mid 42666695$

Email jverbsky@mcw.edu
Abstract: Juvenile idiopathic arthritis (JIA) is a group of disorders characterized by arthritis persisting for at least 6 weeks with onset before the age of 16 years. Within this cluster of conditions, the polyarticular form (involving more than four joints within the first 6 months) is further divided based on the presence of rheumatoid factor. Children with polyarticular JIA pose unique diagnostic and therapeutic challenges compared to children with involvement of fewer joints. Polyarticular JIA patients tend to have a more refractory course and therefore are at increased risk for joint damage, resulting in poorer functional outcomes and decreased quality of life. Although the ability to treat this disorder continues to improve, especially with the advent of biologic agents, there is still much about the epidemiology and pathogenesis of polyarticular JIA that is unknown. The epidemiology of polyarticular JIA varies worldwide with a vast difference in reported cases between different global regions as well as within individual countries. Several genetic risk loci have been identified conferring increased susceptibility to JIA, many within the human leukocyte antigen region. Beyond the genome, environmental factors also seem to contribute to the etiology of polyarticular JIA. This review article will focus on the epidemiology and current treatments of polyarticular JIA and briefly discuss genetic and environmental influences on the pathogenesis of JIA as well as new and emerging therapies.

Keywords: juvenile arthritis, polyarticular, epidemiology, treatment, rheumatology

\section{Introduction}

Juvenile idiopathic arthritis (JIA) is an umbrella-term describing a heterogeneous group of conditions characterized by chronic arthritis beginning before the age of 16 years, persisting for at least 6 weeks, and having no other identifiable cause. ${ }^{1}$ Considered as a whole group, JIA is the most common rheumatologic condition of childhood and consists of subtypes including oligoarticular, polyarticular, and systemic onset. ${ }^{2}$ Polyarticular JIA includes a blend of patients with a wide spectrum of etiologic risk factors, unique disease course, and therapeutic challenges. Children with polyarticular JIA tend to have a more refractory course in comparison to those with fewer affected joints. Due to a prolonged course of active disease, they are at increased risk for joint damage, resulting in poorer functional outcomes and decreased quality of life. ${ }^{3}$ This review focuses on the epidemiology specific to polyarticular JIA, briefly reviews the genetic and environmental risks that contribute to the pathogenesis of this subset of arthritis, and discusses current treatment strategies.

\section{Overview}

To investigate the epidemiology of polyarticular JIA, extensive literature searches of PubMed were performed using the following search terms: epidemiology JIA, incidence 
JIA, prevalence JIA, prognosis JIA, management JIA, and treatment JIA. Emerging treatments were assessed by searching ClinicalTrials.gov, PubMed, and recent abstract supplements from the American College of Rheumatology (ACR) Annual Conference. Articles were excluded from this review if they did not specifically discuss polyarticular JIA.

\section{Classification}

The nomenclature to define childhood arthritis has changed several times over the last 40 years (Table 1). ${ }^{1,4,5}$ The latest definition, as put forth by the International League of Associations for Rheumatology (ILAR) in 1997 and later revised in 2001, divides JIA into seven subgroups. ${ }^{1}$ It defines polyarticular JIA as arthritis affecting five or more joints during the first 6 months of disease. This subgroup is further divided into rheumatoid factor (RF) positive or RF negative, with the former having two or more RF positive tests at least 3 months apart during the first 6 month period. Patients with systemic-onset JIA, psoriatic arthritis, enthesitis-related arthritis, and oligoarticular arthritis who later develop arthritis in multiple joints (extended oligoarticular JIA) can all have polyarticular disease, but they are all excluded from the polyarticular JIA subgroups based on the ILAR classification. Additional exclusions include but are not limited to males who are HLA-B27 positive and have onset of arthritis after their sixth birthday, ankylosing spondylitis, and sacroiliitis with inflammatory bowel disease.

The intent of this current classification system was to create consistency among international providers in order to identify children with similar characteristics for the purposes of research towards epidemiology, pathogenesis, and treatment strategies. Debate, however, is still ongoing as to whether this current scheme is too inclusive and should be further redeveloped with emphasis more on antibody presence, age of symptom onset, and symmetry of arthritis. ${ }^{6}$ With regard to polyarticular JIA, several observations have been made fueling this discussion. Antinuclear antibodies (ANA) in patients with JIA help predict the risk of uveitis, but little is known of their role in the pathogenesis of JIA. Oligoarticular JIA patients who are ANA positive share similar features with ANA-positive, RF-negative polyarticular JIA patients such as younger age at presentation, asymmetric arthritis, and increased frequency of uveitis. ${ }^{7,8}$ In comparison, ANA-negative patients with polyarticular disease tend to present older with a cumulative, symmetrical arthritis, and with a different pattern of joint involvement that more commonly involves the hips and shoulders. The presence of RF is most often seen in the polyarticular subtypes, but when present in oligoarticular patients it has been associated with early erosive disease, suggesting that an RF-positive status should be a subset of its own regardless of the number of joints involved. ${ }^{9}$ The prevalence of anti-cyclic citrullinated peptide (CCP) antibodies varies in polyarticular JIA but usually coincides with RF status. ${ }^{10}$ However, the results of a single study indicated that approximately $6 \%$ of RF-negative patients were also CCP positive and tended to be phenotypically and genetically different from RF-positive, CCP-positive patients, prompting the discussion for the need to reclassify patients not only on RF status but CCP status as well. ${ }^{11}$ Age also appears to be an independent risk factor as younger RF-negative children tend to develop a more aggressive disease course compared to RF-negative children

Table I Classification of chronic arthritis of childhood

\begin{tabular}{|c|c|c|c|}
\hline Organization & European League Against Rheumatism (EULAR) ${ }^{4}$ & $\begin{array}{l}\text { American College of Rheumatology } \\
(A C R)^{5}\end{array}$ & $\begin{array}{l}\text { International League of Associations } \\
\text { for Rheumatology (ILAR)' }\end{array}$ \\
\hline Criteria name & Juvenile chronic arthritis & Juvenile rheumatoid arthritis & Juvenile idiopathic arthritis \\
\hline Year & 1977 & 1986 & 1997, revised 200I \\
\hline Age of onset & $<16$ years & $<16$ years & $<16$ years \\
\hline Duration & $\geq 3$ months & $\geq 6$ weeks & $\geq 6$ weeks \\
\hline Subsets & $\begin{array}{l}\text { I. Pauciarticular: }<5 \text { joints } \\
\text { 2. Polyarticular: }>4 \text { joints, RF- } \\
\text { 3. Systemic: arthritis with characteristic fever } \\
\text { 4. Juvenile rheumatoid arthritis: }>4 \text { joints, RF+ } \\
\text { 5. Juvenile ankylosing spondylitis } \\
\text { 6. Juvenile psoriatic arthritis }\end{array}$ & $\begin{array}{l}\text { I. Polyarthritis: } \geq 5 \text { inflamed joints } \\
\text { 2. Oligoarthritis (pauciarticular } \\
\text { disease): }<5 \text { inflamed joints } \\
\text { 3. Systemic onset: arthritis with } \\
\text { characteristic fever }\end{array}$ & $\begin{array}{l}\text { I. Systemic } \\
\text { 2. Oligoarthritis } \\
\text { a. Persistent } \\
\text { b. Extended } \\
\text { 3. Polyarthritis: RF- } \\
\text { 4. Polyarthritis: RF+ } \\
\text { 5. Psoriatic arthritis } \\
\text { 6. Enthesitis-related arthritis } \\
\text { 7. Undifferentiated } \\
\text { a. Fits no other category } \\
\text { b. Fits more than one category }\end{array}$ \\
\hline
\end{tabular}

Abbreviations: RF-, rheumatoid factor negative; RF+, rheumatoid factor positive. 
who present later in childhood or early adolescence. ${ }^{12}$ These observed variances in polyarticular JIA are purely academic discussion points at this time but may be incorporated into future restructuring of classification schemes. With regard to current practice, all polyarticular patients regardless of RF status are generally managed similarly and studied together in drug trials and consensus treatment plans. ${ }^{13}$

\section{Epidemiology}

Worldwide incidence and prevalence of chronic childhood arthritis are unknown. Epidemiological studies have reported a wide variance in different regions of the world, with low rates in Asian populations ${ }^{14,15}$ and relatively higher frequencies in those of European descent. ${ }^{16,17}$ Vast differences also appear within the same country as demonstrated by polyarticular disease occurring more frequently in southern India as compared to the northern region. ${ }^{18}$ Considering all subtypes of arthritis, the incidence of childhood arthritis ranges from 0.83 per 100,000 children in Japan ${ }^{14}$ to 23 per
100,000 in Norway. ${ }^{19}$ There is an overall trend that this rate is increasing. ${ }^{20}$ Pruunsild et al reported a 3.5 -fold increase over three consecutive years in Estonia. ${ }^{21}$ It is unclear if increased awareness of JIA or actual increase in this disorder is the root cause of this trend. The prevalence varies considerably more spanning from 3.8 per 100,000 children in Taiwan ${ }^{15}$ to 400 per 100,000 in one community-based study in Australia. ${ }^{22}$ The wide variation in data likely reflects the differences amongst clinical epidemiological studies regarding inconsistent use of nomenclature, variance in case ascertainment, difficulties with making accurate diagnoses, as well as patient ability to access health care that results in delays in diagnosis. The paucity of pediatric rheumatology subspecialists worldwide is likely a contributing factor as well.

Large-scale epidemiologic studies have tended to focus on the population of childhood arthritis as a whole, leaving less data available for interpretation on the epidemiology of polyarticular JIA (Table 2). ${ }^{16,17,20,21,23-45}$ Traditionally, polyarticular JIA has been thought to represent approximately $15 \%-25 \%$ of

Table 2 Epidemiologic studies of polyarticular juvenile arthritis

\begin{tabular}{|c|c|c|c|c|c|c|c|c|c|c|c|c|c|}
\hline \multirow[t]{2}{*}{ Country } & \multirow[t]{2}{*}{ Year } & \multicolumn{3}{|c|}{ Percentage of all arthritis } & \multicolumn{2}{|c|}{$\begin{array}{l}\text { Incidence } \\
\text { per } 100,000\end{array}$} & \multicolumn{2}{|c|}{$\begin{array}{l}\text { Prevalence } \\
\text { per } 100,000\end{array}$} & \multicolumn{2}{|c|}{ Girls:boys } & \multicolumn{2}{|c|}{$\begin{array}{l}\text { Mean age at } \\
\text { onset (years) }\end{array}$} & \multirow[t]{2}{*}{ Criteria } \\
\hline & & Polyarticular & RF- & $\mathbf{R F +}$ & RF- & RF+ & RF- & RF+ & RF- & $\mathbf{R F}+$ & RF- & RF+ & \\
\hline Germany $^{23}$ & 2001 & $9.0 \%$ & - & - & 0.28 & - & 1.64 & - & $6: 1$ & - & - & - & EULAR \\
\hline US $(M N)^{24}$ & 1993 & $12.0 \%$ & - & - & 1.67 & - & $13.6^{\mathrm{a}}$ & - & $2: 1$ & - & - & - & ACR \\
\hline Spain ${ }^{25}$ & 2010 & $12.4 \%$ & $10.3 \% \mathrm{a}$ & $2.1 \% \mathrm{a}$ & 0.70 & 0.10 & 3.70 & 0.70 & $|4:|^{a}$ & $3: 0$ & $7.1^{\mathrm{a}}$ & II.3 & ILAR \\
\hline $\mathrm{UK}^{16}$ & 2008 & $15.8 \%$ & $13.4 \%$ & $2.4 \%$ & - & - & - & - & $3.5: 1$ & 4.9:1 & 6.7 & 11.6 & ILAR \\
\hline US $(M N)^{26}$ & 1996 & $17.0 \%$ & - & - & 2.00 & - & - & - & $2.7: 1$ & - & 5.8 & - & $A C R$ \\
\hline France $^{27}$ & 2010 & $18.7 \%$ & $16.7 \%$ & $2.0 \%$ & - & - & 2.60 & 0.31 & $8: 0$ & $\mathrm{I}: 0$ & 9.4 & - & ILAR \\
\hline Belgium $^{28}$ & 1993 & $20.0 \%$ & - & - & - & - & 33.4 & - & - & - & - & - & EULAR \\
\hline Finland ${ }^{20}$ & 2001 & $20.0 \%$ & $20.0 \%$ & $0.0 \%$ & 4.00 & - & - & - & - & - & - & - & EULAR \\
\hline France $^{29}$ & 2006 & $22.4 \%$ & $22.4 \%$ & $0.0 \%$ & 0.71 & - & 4.40 & - & $6.5: 1$ & - & 6.7 & - & ILAR \\
\hline Costa Rica ${ }^{30}$ & 1995 & $23.0 \%$ & - & - & 1.24 & - & - & - & I.5:I & - & - & - & EULAR \\
\hline Canada $^{17}$ & 2005 & $23.7 \%$ & $20.6 \%$ & $3.1 \%$ & - & - & - & - & $2.4: 1$ & 7.5:1 & 6.3 & II.I & ILAR \\
\hline Spain ${ }^{31}$ & 2001 & $24.0 \%$ & $22.4 \%$ & $1.6 \%$ & - & - & - & - & $3.6: 1$ & $2: 0$ & $4.5(\mathrm{M})$ & II.3 (M) & ILAR \\
\hline Estonia $^{32}$ & 2007 & $24.0 \%$ & $19.5 \%$ & $4.5 \%$ & - & - & 16.3 & 3.80 & I.6:I & $8: 1$ & 9.7 & 10.2 & ILAR \\
\hline Estonia $^{21}$ & 2007 & $25.0 \%$ & $20.6 \%$ & $4.4 \%$ & 4.40 & 0.90 & - & - & $2: 1$ & $6: 1$ & 9.9 & 11.5 & ILAR \\
\hline Japan 33 & 1997 & $25.0 \%$ & $12.5 \%$ & $12.5 \%$ & - & - & - & - & - & - & - & - & $A C R$ \\
\hline Germany $^{34}$ & 2001 & $28.5 \%$ & $25.6 \%$ & $2.9 \%$ & - & - & - & - & $3.9: 1$ & $4: 1$ & 5.3 & 11.5 & ILAR \\
\hline India ${ }^{35}$ & 2010 & $28.9 \%$ & $17.4 \%$ & I I.5\% & - & - & - & - & I.6:I & $8: 1$ & II.5 (M) & $13.0(\mathrm{M})$ & ILAR \\
\hline Egypt $^{36}$ & 2013 & $29.5 \%$ & $21.2 \%$ & $8.3 \%$ & - & 0.72 & - & 0.28 & I.6:I & $2: 1$ & 9.1 & 11.5 & ILAR \\
\hline Canada $^{37}$ & 1995 & $34.9 \%$ & - & - & 1.85 & - & - & - & - & - & - & - & $A C R$ \\
\hline Sweden ${ }^{38}$ & 1995 & $35.0 \%^{\mathrm{a}}$ & $29.2 \%^{\mathrm{a}}$ & $5.8 \%^{a}$ & 2.24 & 0.46 & 18.7 & 10.3 & $2: 1$ & $8: 1$ & $9.0(\mathrm{M})$ & - & EULAR \\
\hline Turkey $^{39}$ & 2008 & $37.2 \%$ & $30.6 \%$ & $6.6 \%$ & - & - & - & - & $0.8: 1$ & 2.3:1 & 5.7 & 10.4 & ILAR \\
\hline South Africa ${ }^{40}$ & 2013 & $41.0 \%$ & $26.9 \%$ & $14.1 \%$ & - & - & - & - & - & - & $8.0(\mathrm{M})$ & $10.0(\mathrm{M})$ & ILAR \\
\hline Kuwait ${ }^{41}$ & 1990 & $42.0 \%$ & - & - & - & - & - & - & - & - & - & - & EULAR \\
\hline Zambia $^{42}$ & 2013 & $46.1 \%$ & $34.6 \%$ & I I.5\% & - & - & - & - & I.7:I & $9: 1$ & 10.7 & 11.0 & ILAR \\
\hline Czech Republic ${ }^{43}$ & 2006 & $50.0 \%$ & - & - & 6.50 & - & - & - & $2: 0$ & - & 9.5 & - & ILAR \\
\hline India ${ }^{44}$ & 1994 & $51.7 \%$ & $34.8 \%$ & $16.9 \%$ & - & - & - & - & I.6:I & - & 11.0 & - & EULAR \\
\hline Nigeria $^{45}$ & 2010 & $57.0 \%$ & - & - & - & - & - & - & - & - & - & - & ILAR \\
\hline
\end{tabular}

Note: a Range reported with upper limit displayed in table.

Abbreviations: ACR, American College of Rheumatology; EULAR, European League Against Rheumatism; ILAR, International League of Associations for Rheumatology; RF-, rheumatoid factor negative; RF+, rheumatoid factor positive; M, median reported instead of mean; MN, Minnesota; -, not applicable. 
JIA as indicated in North American and European studies. ${ }^{16,17}$ Roughly $15 \%$ of this subset tests positive for $\mathrm{RF}$, with a relative frequency of RF-positive disease around 3\% of all JIA cases. Polyarticular disease, however, has been reported as the predominant form of chronic childhood arthritis in several locations, including Africa, ${ }^{40,42,45}$ Czech Republic, ${ }^{43}$ Kuwait, ${ }^{41}$ and India, ${ }^{44}$ with frequencies approaching or exceeding $50 \%$. Furthermore, RF-positive disease also tends to be higher in these populations, with reports of this subtype in $14.1 \%$ of all South African ${ }^{40}$ cases and $16.9 \%$ of Indian ${ }^{44}$ cases. RF-positive polyarticular JIA may be misrepresented in these regions as the diagnosis is generally made after checking RF status only once due to the constraints on resources and inability to repeat laboratory testing. ${ }^{40}$ Many affected individuals in these populations also present late, after several years of arthritis. ${ }^{42}$ This too could lead to misclassification as several cases likely represented oligoarticular patients with extended disease who would have been diagnosed differently if seen within the first 6 months of disease onset. Given the variance of relative frequency of polyarticular disease and the sparse data regarding epidemiological data, the incidence of RF-negative disease has been calculated to range from $0.3-6.5$ per 100,000 and RFpositive disease from $0.1-0.72$ per $100,000 .^{20,21,23-26,29,30,36-38,43}$ Spanning different populations, the prevalence of RF-negative disease varies from 1.64-33.4 per 100,000 and RF-positive disease from $0.28-10.3$ per 100,000..$^{23-25,27-29,32,36,38}$

By definition, polyarticular JIA can begin any time before the age of 16 years but rarely occurs before the first year of life. The onset of the RF-negative subtype follows a bimodal distribution, with the first peak occurring between 1-3 years of age, and the second peak occurring in later childhood between 9-14 years of age. ${ }^{37}$ Girls are affected two to four times more often than boys, with this ratio skewed even further towards females when the onset of disease occurs in the teenage years. Conversely, RF-positive JIA tends to be a condition affecting older children, with the onset of disease typically between 10-13 years of age. There is a much higher preponderance of females affected with RF-positive disease outnumbering their male counterparts 8-9:1, with several epidemiologic studies reporting only female cases of RF-positive disease and no male patients. . $^{25,27,31}$

Additional observations and trends regarding the incidence of all subtypes of JIA have been made without a clear etiologic role. The prevalence of JIA has been reported to be higher in urban settings, ${ }^{36,43}$ by up to 2.7 times in a Danish study. ${ }^{46}$ That same study indicates that JIA patients are 1.6 times more likely to be an only child, and they tend to be from a higher socioeconomic status, with families of JIA patients reporting higher incomes twice as often than controls. This financial trend has been reproduced in a Canadian study as well. ${ }^{47}$ Studies assessing the seasonal variation in JIA onset identify the winter months as the peak time of year for new cases of JIA to present. ${ }^{48}$ Additional work is needed to confirm and further investigate the factors that contribute to these observations.

\section{Natural history and prognosis}

The disease course and prognosis of JIA remain variable but have improved with the development of new therapies. The first 6 months of disease can be quite dynamic as patients can often accumulate arthritis in new joints not initially involved at disease onset. As a result, the JIA subtype is not definitive until 6 months after onset. ${ }^{1}$ A long-term JIA cohort study lasting 17 years demonstrated outcomes were best predicted by features of disease at 5-year follow-up compared to disease onset. ${ }^{49}$

Several variables including type of JIA affect the goal of disease remission. In a cohort study of 683 JIA patients, $32.8 \%$ were in remission after a mean follow-up of 10 years, with remission being defined as no disease activity in the absence of antirheumatic medications for at least 6 months. ${ }^{50}$ The polyarticular subtype, making up $15.8 \%$ of the cohort, attained remission in $24.1 \%$ of patients at some time in the disease course. Interestingly, none of the RF-positive patients achieved remission during the time course studied. A similar study in 392 JIA patients determined the probability of remission - defined as absence of arthritis off treatment for at least 2 years - at 10 years was $23 \%$ for RF-negative polyarticular patients and $6 \%$ for RF-positive polyarticular patients. ${ }^{51}$ A more recent study assessed JIA patients transitioned to adult providers. ${ }^{52}$ A majority of those patients had evidence of disease activity within the past year despite $29 \%$ being on biologic therapy for a median of 4 years. Other long-term studies report development of erosions in $24 \%$ of JIA patients and probability of arthroplasty after 15 years of active disease ranging from $13 \%-57 \% .^{51,53}$

Features of poor prognosis for polyarticular JIA, as highlighted in the ACR recommendations for JIA based off medical literature and clinical experience, include positive RF antibodies, positive anti-CCP antibodies, hip arthritis, cervical spine arthritis, and erosions or joint space narrowing on radiographs. ${ }^{50,53-56}$ Other factors associated with a poor prognosis include early hand involvement and radiographic changes of carpal length within the first year of diagnosis. ${ }^{57,58}$ 
On the contrary, positive ANA was associated with less disability. ${ }^{57}$ Sex and age of onset have not consistently been linked to prognosis. ${ }^{50,59}$

A long-term follow-up of 246 adults with long-standing JIA and average disease duration of 28.3 years evaluated functional and health-related quality of life outcomes. ${ }^{60-62}$ Severe disability - based off a score on a Health Assessment Questionnaire - was present in $42.9 \%$ of patients. Almost $33 \%$ of the patients were in severe pain and over $25 \%$ of patients were currently or previously depressed. In addition, educational achievement was higher than the national average, although unemployment was twice as high in the JIA patients. A statistically higher rate of unemployment was also noted in another study despite comparable education. ${ }^{53}$ Mortality among patients with JIA is mildly elevated compared to the general population. A single-center, 20-year follow-up study from 1981-2000 noted increased standardized mortality ratios (the ratio of observed to expected deaths) in males (3.4) and females (5.1) with JIA. ${ }^{63}$ Causes of death were not discussed.

\section{Pathogenesis}

Understanding of the genetic basis of JIA is incomplete. As technology improves, as with the advent of genome-wide association studies, the underlying genetic susceptibility factors for JIA are beginning to be defined. ${ }^{64}$ Familial JIA itself is uncommon and does not follow any Mendelian modes of inheritance. One American registry identified 200 sets of siblings with juvenile arthritis over a 10 -year period of whom 21 sets were twins. ${ }^{65}$ The National Institute of Arthritis and Musculoskeletal and Skin Diseases research registry for JIA affected sibling pairs estimates the sibling recurrence risk at 15 with a concordance for polyarticular disease of $31 \%{ }^{66}$ Another study using the Utah Population Database with 862 JIA patients estimates the population attributable risk of familial factors for JIA to be $13 \%$, and the specific risk for polyarticular JIA was $6 \%{ }^{67}$ The relative risk of JIA in the siblings of patients was 11.6. The estimated relative risk for polyarticular JIA was precluded due to the small sample sizes. In addition, the occurrence of JIA and adult rheumatoid arthritis (RA) in the same family is rarely reported.

The major histocompatibility complex (MHC) is a diverse and complex genetic loci central to immunity and inflammatory processes. The MHC comprises genes related to antigen presentation including human leukocyte antigens (HLA) A, B, C, DR, DP, and DQ, minor HLA antigens, as well as other genes important in immune function such as tumor
Table 3 Human leukocyte antigen alleles associated with polyarticular juvenile idiopathic arthritis

\begin{tabular}{|c|c|c|}
\hline Allele & Subtype & Association \\
\hline$A 2^{68,69}$ & RF- & Susceptibility for early onset \\
\hline DPBI $* 03^{68,71}$ & RF- & Susceptibility \\
\hline $\mathrm{DRBI} * 0 \mathrm{I}^{70}$ & RF- & Susceptibility \\
\hline DRBI*0IOI ${ }^{70}$ & RF+ & Susceptibility, shared with adult RA \\
\hline DRBI $* 04^{68,72}$ & $\mathrm{RF}+$ & Susceptibility \\
\hline DRBI $* 040 I^{71-73}$ & RF- & Protective \\
\hline DRBI $* 040 I^{70}$ & $\mathrm{RF}+$ & Susceptibility, shared with RA \\
\hline DRBI $* 0404^{70}$ & $\mathrm{RF}+$ & Susceptibility \\
\hline DRBI*040570 & RF+ & Susceptibility \\
\hline DRBI $* 0408^{70}$ & $\mathrm{RF}+$ & Susceptibility shared with RA \\
\hline DRB $\mid * 07^{72,73}$ & $\mathrm{RF}-, \mathrm{RF}+$ & Protective \\
\hline DRBI*08 $8^{68,72,73}$ & RF- & Susceptibility for late onset \\
\hline $\mathrm{DRB}|*| 103^{73}$ & RF- & Susceptibility for early onset \\
\hline DRBI*I $104^{73}$ & RF- & Susceptibility for early onset \\
\hline DRBI* $\mid 402^{70}$ & $\mathrm{RF}+$ & Susceptibility, shared with adult RA \\
\hline DRBI* $|50|^{73}$ & RF- & Protective \\
\hline DQA $\mid * 02^{68,72}$ & $\mathrm{RF}+$ & Protective \\
\hline DQAI $* 03^{68,72}$ & $\mathrm{RF}+$ & Susceptibility \\
\hline DQAI*0 $4^{68,72}$ & RF- & Susceptibility \\
\hline DQAI*0 $05^{72}$ & $\mathrm{RF}+$ & Susceptibility \\
\hline $\mathrm{DQBI} * 03^{68}$ & $\mathrm{RF}+$ & Susceptibility \\
\hline $\mathrm{DQBI} * 03^{72}$ & RF- & Protective \\
\hline
\end{tabular}

Abbreviations: RA, rheumatoid arthritis; RF-, rheumatoid factor negative; RF+ rheumatoid factor positive.

necrosis factor (TNF). The HLA region has been identified as a major susceptibility locus for JIA (Table 3). ${ }^{68-73}$ It has been estimated to account for up to $13 \%$ of genetic risk of $\mathrm{JIA}^{64}$ as compared to up to a third for adult RA. ${ }^{70}$ HLA interactions in JIA are complex with certain alleles strongly associating with early-onset disease and other alleles providing a protective effect early in life but are associated with increased susceptibility later in childhood. ${ }^{69}$ This variation in disease onset indicates that there are certain windows of susceptibility in the pathogenesis of JIA depending on one's genetic makeup. Sex also seems to influence HLA susceptibility alleles. HLAB27 confers an age-related risk in males, while HLA-A2 is seen in younger female patients with oligoarticular JIA. ${ }^{69}$

With regard to polyarticular JIA, HLA-A2 has been linked with early-onset RF-negative disease, but to a lesser extent than its association in oligoarticular patients. ${ }^{68,69}$ The RF-negative profile overlaps more with that of oligoarticular JIA (A2, DRB1*08, DQA1*04), suggesting that RF-negative disease may be more closely related to oligoarticular disease than the RF-positive subtype. Polymorphisms in class II HLA alleles demonstrate the strongest association with polyarticular disease. ${ }^{68,70-73}$ HLA-DR4 is frequently associated with RF-positive disease, as in adults. ${ }^{68,70,72}$ RF-negative 
disease is more heterogeneous, with susceptibilities linked to HLA-DPB1*03, HLA-DRB1*01, and HLA-DQA1*04 ${ }^{68,70,71}$ Protective associations have also been identified for both RF-negative and RF-positive diseases as well, including DRB1 and DQA1. ${ }^{68,71-73}$

Despite the vast number of polymorphisms identified in the HLA region, these alleles have only been able to account for approximately $20 \%$ of the genetic basis based on sibling recurrence risk in polyarticular and oligoarticular cases. ${ }^{74}$ Beyond the HLA region, a number of additional risk loci have been identified in genes responsible for immune regulation. PTPN22 encodes a lymphoid-specific phosphatase which is a negative regulator of T-cell receptor signal transduction. In RF-negative patients, a missense single nucleotide polymorphism in PTPN22 reduces the ability of this protein to downregulate T-cell activation. ${ }^{75}$ This mutation results in failure to remove potentially autoreactive T-cells during thymic selection. ${ }^{76}$ Another single nucleotide polymorphism identified in STAT4 has been demonstrated in some polyarticular JIA populations of certain ethnicities. ${ }^{77,78}$ STAT4 is a transcription factor expressed in lymphocytes that is required for interleukin (IL)-12 responsiveness and Th1 development. Variation in the loci encoding TRAF1 and C5 - located at chromosome 9q33-34 - can occur in both RF-positive and RF-negative cohorts. There appears to be a more significant association of this mutation with the RF-negative phenotype. ${ }^{79}$ On the other hand, a polymorphism in the promoter region of TNF $\alpha$ (TNF-308A) is less commonly found in RFnegative disease as compared to RF-positive polyarthritis, and has been linked to more severe disease. ${ }^{80}$ Many RF-positive JIA individuals tend to share additional non-HLA loci with the adult RA population. ${ }^{81}$ Furthermore, most identified polymorphisms in JIA are shared across other autoimmune disorders, such as diabetes mellitus type 1, autoimmune thyroid disease, inflammatory bowel disease, and systemic lupus erythematosus..$^{65,77,82}$

In the setting of a genetically susceptible individual, environmental influences are hypothesized to contribute to JIA pathogenesis. There has been particular interest in the relationship between breastfeeding and the development of JIA, and studies to date have been conflicting. Breast milk contains immune-modulatory compounds such as immunoglobulins, chemokines, and cytokines. ${ }^{83}$ Mason et al conducted a small study of 54 JIA patients and 79 matched controls, concluding that duration of breastfeeding provided a protective effect toward the development of JIA (odds ratio [OR] 0.40; 95\% confidence interval [95\% CI] $0.20-0.81) .{ }^{84}$ The effect was less pronounced in polyarticular cases $(n=24$; OR 0.60 ;
95\% CI 0.21-1.70). This study was prone to criticism due to small sample size, low statistical power, and selection bias of controls. A similar study evaluating 137 Canadian children with JIA compared to 331 controls revealed no significant differences between breastfeeding in JIA cases and controls (68\% versus 62\%). ${ }^{85}$ However, a lower proportion of polyarticular patients were found to be breastfed in comparison to oligoarticular patients $(53 \%$ versus $76 \%$; $P=0.006)$, although polyarticular patients were breastfed for longer durations on average (7.3 months versus 5.9 months). No studies have directly evaluated breastfeeding practices specifically in RF-positive JIA patients. In a retrospective study assessing multiple risk factors for RF positivity in healthy children, there was a correlation noted between RF status and breastfeeding among children who were HLA-DR4 negative. ${ }^{86}$ Breastfeeding for more than 3 months was more frequent in RF-negative children than RF-positive children (OR 0.18; 95\% CI 0.04-0.99). A similar protective effect has been linked to the initiation of early breastfeeding with a decreased risk of adult-onset RA. ${ }^{87}$

Tobacco smoke has been shown to be a strong risk factor in the development of RA in adults. ${ }^{88}$ This has been thought to be mediated through RF production. ${ }^{89}$ In one retrospective study assessing risk factors for RF-positivity in children, HLA-DR4-negative children who were RF-positive were five times more likely to have been exposed to environmental tobacco smoke compared to RF-negative children. ${ }^{86}$ Tobacco has a direct effect on the immune system leading to a reduction in the number of natural killer cells and abnormalities in T-lymphocyte function and humoral immunity. ${ }^{90}$ Several studies have assessed the relationship between maternal smoking during pregnancy and the risk of JIA in the offspring. . $^{91,92}$ Jaakkola and Gissler followed a cohort of 58,841 Finnish children from birth, identifying 31 cases of JIA. ${ }^{91}$ They concluded there was a two-fold higher risk of developing JIA during the first 7 years of life in children of mothers who smoked greater than ten cigarettes per day compared to children of nonsmoking mothers. When female cases were compared to unexposed males, the risk increased to six-fold. A larger prospective study, however, did not demonstrate an associated risk between maternal smoking and JIA. ${ }^{92}$

Other perinatal exposures and pregnancy-related factors have been investigated. ${ }^{47,92}$ An Australian study that reviewed 262 cases and matched controls identified a trend towards a protective effect with prenatal nutritional supplements. ${ }^{47}$ The mothers of children that eventually developed JIA were less likely to receive supplementation with prenatal multivitamins (24.9\% versus $30.8 \%$ ), vitamin D (3.3\% versus $7.8 \%)$, fish 
oil ( $2.9 \%$ versus $6.4 \%)$, calcium ( $10.2 \%$ versus $14.9 \%)$, iron (35.4\% versus $40.3 \%)$, and folate $(61.4 \%$ versus $64.8 \%)$ while pregnant compared to controls. None of these effects were found to be statistically significant when adjusted for covariates. In addition, there were equal rates of antibiotic, alcohol, and caffeine use. A larger Swedish study included 3,334 JIA patients and 13,336 controls..$^{92}$ Borderline risks were found for Cesarean section (OR 1.1; 95\% CI 1.0-1.3) and birth at 42 weeks gestational age or later (OR 1.3; 95\% CI 1.0-1.3). Reduced risk was seen in patients with low Apgar score $(<6)($ OR $0.7 ; 95 \%$ CI $0.5-1.0)$. This study did not detect a significant difference in maternal age, marital status, season of birth, birth order, or birth weight.

Psychosocial factors and stressful life events have been implicated as triggers for the onset of JIA. ${ }^{93-97}$ One of the earliest reported studies evaluated eight pairs of monozygotic twins discordant for chronic arthritis. ${ }^{94}$ The twin with arthritis reported significantly higher rates of psychological stressors prior to onset of arthritis compared to the healthy twin. A survey of children with chronic arthritis revealed a high rate of parental divorce, separation, or death in $28.4 \%$ as compared to $10.6 \%$ of the controls, with half of the events occurring close to the onset of JIA. ${ }^{95}$ Most recently, Neufeld et al demonstrated that a sample of 685 JIA patients were more likely to experience serious emotional hardships preceding the first clinic visit in comparison to 1,042 controls. ${ }^{96}$ RF-negative polyarticular JIA patients were more likely to experience hardship (OR 5.68) compared with oligoarticular JIA patients (OR 3.32), with parental separation or death occurring most frequently. RF-positive patients did not show the same pattern, leading to speculation that age may be a determining factor at the time of a stressful event. RF-positive children tend to be older, therefore the younger cohort may be more vulnerable to stress, rendering them more susceptible to later alterations of immune and inflammatory responses.$^{98}$ Stress has been demonstrated in JIA patients to increase leukocyte production of IL-6, a potent cytokine in the pathogenesis of JIA. Although the mechanism of how stress affects the development of autoimmune diseases is unknown, peripheral blood mononuclear cells in JIA patients were shown to have increased expression of $\alpha 1$-adrenergic receptors compared to non-JIA patients, possibly contributing to this finding. ${ }^{99}$

Infections have a clear inciting role in some forms of arthritis, such as group A streptococcal infections with acute rheumatic fever or Chlamydia trachomatis resulting in reactive arthritis. Several pathogens can lead to a transient and usually self-limited postinfectious arthritis..$^{100}$ In more chronic conditions, infections have been demonstrated to influence the development of autoimmunity, as in systemic lupus erythematosus and Sjogren's syndrome. ${ }^{101,102}$ The mechanism of how infection leads to autoimmunity is complex and multifaceted. Molecular mimicry, in which infectious agents display an epitope structurally similar to that of a self antigen, has been proposed to trigger a strong immunologic response, particularly within the synovium. ${ }^{103}$ Localized inflammatory reactions to invading pathogens can activate antigen-presenting cells, which can promote and activate autoreactive lymphocytes. Polyclonal expansion of B-cells in response to bacterial components results in a vast array of antibody production. ${ }^{102}$

By definition, JIA is idiopathic with no identifiable cause; nevertheless, several microbial agents, particularly viruses, have been associated with the onset of JIA and suggested to initiate or augment this chronic disorder. In one epidemiologic study on the incidence of JIA in Estonia, 31\% of the 162 new cases of JIA had a documented infection prior to the onset of arthritis. ${ }^{21}$ Although the specific type of infection was not discussed in this study, others have observed infections with influenza A, rubella, parvovirus B19, Epstein-Barr virus (EBV), and Mycoplasma pneumoniae to correlate with chronic juvenile arthritis. ${ }^{37,104-107}$ Some studies have demonstrated persistence of infectious markers within synovial fluid. ${ }^{105,108}$ However, many reports rely on the identification of serologic antibodies to viruses, and interpretation of seropositivity can be controversial. For example, both EBV and influenza A have specific implications with regard to the pathogenesis of polyarticular JIA. One study of 50 hospitalized patients with JIA identified 44 of them to be infected with EBV, with $75 \%$ of the infected patients having polyarticular disease, leading to the conclusion that patients with EBV are at greater risk of developing juvenile arthritis. ${ }^{107}$ There was no comment on a control group. On the other hand, a study of 41 JIA patients with predominantly polyarticular disease identified a smaller cohort within the study population who were born in the same year as an influenza A epidemic. ${ }^{104}$ These patients were found to have higher influenza A antibody levels than age-matched controls and JIA patients born in other years. No elevation was found in three other control viruses. These patients developed arthritis after the appearance of a different strain of influenza A, leading the authors to suggest they had been presensitized to influenza via neonatal or prenatal exposure and reintroduction of the virus triggered the onset of JIA. These studies should be interpreted with caution since these are common infections and most people have been exposed to these pathogens at some point in their life. 


\section{Current and emerging treatment options}

The number of medications used to treat polyarticular JIA has expanded in recent years due to the use of biologic therapies that selectively target the inflammatory pathway (Table 4). The goal of therapy includes disease remission, pain control, and improved functioning while balancing the side effects of medications.

In 2011, the ACR published recommendations for the treatment of JIA based on disease subtype (ie, oligoarticular disease, polyarticular disease, sacroiliac arthritis, and systemic onset JIA) ${ }^{54}$ However, variability in treatment of polyarticular JIA remains. Recently, the Childhood Arthritis and Rheumatology Research Alliance (CARRA) developed consensus treatment plans for new-onset polyarticular JIA to address this concern and try to optimize care based off comparative effectiveness studies. ${ }^{13}$

\section{Current treatments}

\section{Nonsteroidal anti-inflammatory drugs (NSAIDs)}

NSAIDs continue to be the most commonly used class of medicine in inflammatory arthritides, including JIA. NSAIDs block prostaglandin formation via inhibition of cyclooxygenase-1 and cyclooxygenase-2, leading to both analgesic and anti-inflammatory properties. NSAID monotherapy is indicated per ACR recommendations for up to 2 months

Table 4 Medications for treatment of polyarticular juvenile idiopathic arthritis

\begin{tabular}{|c|c|c|c|}
\hline Medication & Mechanism of action & Route & Type \\
\hline Abatacept & $\begin{array}{l}\text { Binds to CD80/CD86 and inhibits } \\
\text { T-cell costimulatory signal }\end{array}$ & IV, SQ & Biologic \\
\hline Adalimumab & TNF inhibitor & $\mathrm{SQ}$ & Biologic \\
\hline Etanercept & TNF inhibitor & SQ & Biologic \\
\hline Glucocorticoids & $\begin{array}{l}\text { Decreases transcription of } \\
\text { cytokines; many others }\end{array}$ & Oral, IA & Other \\
\hline Infliximab & TNF inhibitor & IV & Biologic \\
\hline Leflunomide & Pyrimidine synthesis inhibitor & Oral & DMARD \\
\hline Methotrexate & $\begin{array}{l}\text { Dihydrofolate reductase } \\
\text { inhibitor; inhibits DNA } \\
\text { synthesis; many others }\end{array}$ & Oral, SQ & DMARD \\
\hline NSAIDs & Blocks prostaglandin formation & Oral & Other \\
\hline Rituximab & Binds CD20 on B-cells & IV & Biologic \\
\hline Sulfasalazine & $\begin{array}{l}\text { Interferes with formation of } \\
\text { leukotrienes and prostaglandins, } \\
\text { causes accumulation of } \\
\text { adenosine; inhibits bacterial } \\
\text { growth; others proposed }\end{array}$ & Oral & DMARD \\
\hline Tocilizumab & IL-6 inhibitor & IV, SQ & Biologic \\
\hline
\end{tabular}

Abbreviations: DMARD, disease modifying antirheumatic drug; IA, intra-articular; IL, interleukin; IV, intravenous; NSAIDs, nonsteroidal anti-inflammatory drugs; SQ, subcutaneous. depending on disease activity. ${ }^{54}$ In addition, NSAIDs are often used in conjunction with disease-modifying antirheumatic drugs (DMARDs) and/or biologic therapy.

\section{Glucocorticoids}

Glucocorticoids have a limited role in the treatment of JIA. Steroid injections are given frequently in patients with a few involved joints (oligoarticular JIA), which can lead to sustained responses or remission without other therapy. ${ }^{54}$ Intra-articular steroids can also be given as adjunct therapy for children with polyarticular JIA with a few problematic joints even if on other immunosuppressive agents. Triamcinolone hexacetonide is the recommended long-acting corticosteroid, and improvement with this treatment modality should last for at least 4 months. ${ }^{54,109}$

Systemic glucocorticoids are not routinely recommended for treatment of polyarticular JIA per ACR recommendations; however, it may be a component of early aggressive therapy for severe disease in addition to providing symptomatic relief while other medications are started. ${ }^{54,110}$ The CARRA consensus treatment plans include optional prednisone at diagnosis at the lowest possible dose in each plan in conjunction with other therapy. ${ }^{111}$ Recommendations are to taper quickly, by 3 months if possible. Overall, the use of steroids is limited by its side effect profile.

\section{DMARDs}

Methotrexate has historically been second-line therapy for JIA following a course of NSAIDs. However, it may be indicated as first-line therapy for severe polyarticular disease or avoided altogether for newer approaches using biologics as first- or second-line medications. ${ }^{13,54}$ Methotrexate is an antimetabolite with anti-inflammatory and immunomodulatory properties. It is a folic acid analog and inhibitor of dihydrofolate reductase that interferes with purine biosynthesis. Methotrexate also inhibits adenosine deaminase leading to accumulation of adenosine, among other mechanisms. ${ }^{12}$ Methotrexate was first found to be effective in children with JIA through a randomized, double-blind, placebo-controlled trial in 1992. ${ }^{113}$ Subsequent studies have demonstrated similar results and efficacy. ${ }^{114,115}$

Leflunomide is often considered an alternative treatment option for methotrexate. ${ }^{54}$ Leflunomide inhibits dihydroorotate dehydrogenase, which subsequently inhibits pyrimidine synthesis, among other mechanisms. ${ }^{112}$ One randomized, controlled trial comparing leflunomide and methotrexate showed that both resulted in high rates of clinical improvement, but methotrexate was more effective. ${ }^{116}$ 
A majority of patients in a different open-label study who failed to respond to, or were intolerant of, methotrexate met improvement criteria with leflunomide. ${ }^{117}$

Several other DMARDs have been studied in JIA patients including sulfasalazine, hydroxychloroquine, penicillamine, azathioprine, cyclosporine, tacrolimus, and thalidomide. ${ }^{118-}$ ${ }^{123}$ The use of these medications is not routine therapy and may be used in refractory disease or in non-polyarticular JIA in certain circumstances. ${ }^{54}$ Sulfasalazine in particular may be of benefit in the enthesitis-related subtype of JIA. In addition, combination DMARDs, which often include methotrexate, sulfasalazine, and hydroxychloroquine, are used in the treatment of RA and were recently found to be noninferior to a combination of TNF inhibitor and methotrexate in a double-blind trial in adults. ${ }^{124}$ These options may be useful when biologics are cost prohibitive.

\section{Biologics}

TNF inhibitors

TNF inhibitors are one of the best studied biologic medications for the treatment of JIA. TNF $\alpha$ is a proinflammatory cytokine elevated in the serum and synovial fluid of JIA patients. ${ }^{12,125-129}$ Three specific medications - etanercept, infliximab, and adalimumab - have demonstrated efficacy in randomized, placebo-controlled trials in JIA. This class of medicine is recommended after incomplete response to methotrexate per 2011 guidelines. ${ }^{54}$ However, two other randomized clinical trials evaluated the use of biologics early in the disease course as aggressive therapy for polyarticular JIA. ${ }^{110,126}$ One study found the treatment group with infliximab plus methotrexate was superior to combination DMARD therapy and solo methotrexate. ${ }^{126}$ The other study noted a substantial portion of patients treated aggressively with etanercept, methotrexate, and prednisolone had clinical remission on medication within 12 months, although the primary study endpoint was not met. ${ }^{110}$ Currently anti-TNF agents are recommended after methotrexate except for cases of severe disease.

Etanercept is a human, dimeric soluble protein that contains the human p75 TNF receptor fused to the immunoglobulin G Fc domain. ${ }^{112}$ Lovell et al published the first randomized, double-blind trial of etanercept for treatment of polyarticular JIA in 2000 with promising results. ${ }^{125}$ This initial study, along with others, suggests approximately $70 \%$ of children will respond to etanercept. ${ }^{112}$ A prospective observational study reported greater responses to etanercept in subjects with low baseline disability scores, prior DMARD use, and younger age of disease onset. ${ }^{127}$
Infliximab is a chimeric antibody that specifically binds soluble and membrane-bound TNF $\alpha .{ }^{112,128}$ A randomized, placebo-controlled trial of methotrexate and infliximab for the treatment of polyarticular JIA did not meet its primary outcome; however, an improvement in the majority of patients was noted at 1 year. ${ }^{128}$ Adalimumab is a humanized monoclonal antibody that binds to TNF. A randomized, placebo-controlled trial in 2008 was performed on polyarticular JIA patients taking adalimumab with or without methotrexate and noted statistically significant improvements. ${ }^{129}$

\section{Abatacept}

Abatacept is a human fusion protein of the Fc portion of immunoglobulin G and CTLA-4, which binds to CD80/86 and blocks a crucial step in T-cell activation. ${ }^{112}$ Abatacept was recommended for polyarticular disease after failure of a TNF inhibitor after 4 months of therapy. ${ }^{54}$ However, the recent consensus treatment plans suggest using abatacept as an alternative to a TNF inhibitor following DMARD therapy or early in the disease. ${ }^{13}$ Ruperto et al published the first randomized, double-blind, placebo-controlled withdrawal trial on abatacept for treatment of children with JIA who failed previous treatments and noted statistically decreased number of flares of arthritis in the abatacept group. ${ }^{130}$ Improvements in health-related quality of life were also observed in JIA patients treated with abatacept during a double-blind, placebo-controlled trial. ${ }^{131}$

\section{IL-6 inhibitor}

Tocilizumab is a monoclonal antibody to the IL-6 receptor. IL-6 is a proinflammatory cytokine that has been correlated with disease activity, particularly in systemic JIA. ${ }^{112}$ Although more studies exist on its treatment of systemic JIA, tocilizumab is also approved by the US Food and Drug Administration for treatment of polyarticular disease. ${ }^{132,133}$ A randomized, placebo-controlled trial of tocilizumab on JIA patients with a polyarticular course was found to be efficacious with sustained clinical improvement over 2 years. ${ }^{134,135}$

\section{Rituximab}

Rituximab is a chimeric monoclonal antibody that binds the B-cell CD20 receptor, thus depleting B-cells. ${ }^{112}$ Rituximab is recommended as a possible treatment option after failure of other biologics or earlier in the disease course for aggressive management of polyarticular disease. ${ }^{13,54}$ Efficacy was noted in one clinical study of rituximab on JIA patients refractory to other therapy. ${ }^{136}$ 


\section{Other}

Other biologic therapies utilized for JIA included intravenous immunoglobulin and IL-1 inhibitors. Intravenous immunoglobulin, which is prepared from pooled human plasma, showed a short duration of benefit in a clinical study of polyarticular JIA. ${ }^{137}$ IL-1 inhibitors have been shown to be effective in adult RA, but a randomized multicenter study in polyarticular-course JIA patients reported a trend toward reduction in disease flares that did not reach significance compared to placebo, possibly due to limited enrollment. ${ }^{138,139}$ IL-1 inhibitors, however, have shown significant efficacy in treatment of systemic onset JIA. ${ }^{140-143}$ Specific IL-1 inhibitors recommended for systemic JIA treatment include anakinra, canakinumab, and rilonacept. ${ }^{144}$

\section{Emerging treatments}

Additional DMARD and biologic agents are being developed and studied every year. Two newer TNF inhibitors - certolizumab pegol and golimumab - have been studied more extensively in RA with promising results. ${ }^{145,146} \mathrm{~A}$ multicenter, open-label study of certolizumab pegol is underway in children with severe polyarticular-course JIA. ${ }^{147}$ Similarly, a randomized, double-blind study is ongoing for golimumab treatment in polyarticular JIA with results at 48 weeks not reaching its primary endpoint; however, improvements were noted on an imaging substudy. ${ }^{148,149}$

Tofacitinib, a JAK inhibitor that blocks signaling of multiple cytokines, has shown promising results and is approved for the treatment of RA. ${ }^{150}$ A long-term open-label study of tofacitinib is currently enrolling JIA patients to assess safety and tolerability of this medicine in the pediatric population. ${ }^{151}$ Another JAK1 selective inhibitor, GLPG0634, has undergone Phase II trials in adults and is currently enrolling patients for an open-label, long-term, follow-up study for the treatment of moderate to severe RA. ${ }^{152,153}$

An oral histone deacetylase inhibitor, givinostat, has also been studied in RA and JIA. ${ }^{154,155}$ Additional medications specifically studied in adult RA with recent Phase II/III studies include a CCR1 antagonist (CCX354-C), a Syk inhibitor (fostamatinib), and anti-IL-17 antibody (ixekizumab). ${ }^{156-159}$

\section{Future implications and conclusion}

Research on JIA has lagged behind that of adult onset RA and other autoimmune disorders of childhood, in part perhaps because of the early belief that juvenile arthritis was an extension of adult RA. Similarly, with JIA being a relatively uncommon disease, the evolving and inconsistent nomenclature made it difficult to extrapolate epidemiologic data between smaller populations or for research centers to share information. Now with a seemingly widespread accepted nomenclature for JIA using the ILAR criteria, efforts have focused on the formation of patient registries to generate large-scale study populations. The advent of such networks is helping to identify patient populations at risk for JIA to determine genetic and environmental influences on its pathogenesis, and to establish treatment outcomes given the expanding arsenal of medications currently available to treat this disorder.

The ChiLdhood Arthritis Risk factor Identification sTudY (CLARITY) is an Australian biobank aimed at investigating early-life exposures and patient environment at disease onset. ${ }^{47}$ Blood specimens are prospectively collected for genetic and biomarker analysis at the time of enrollment. On a grander scale, the Pediatric Rheumatology INternational Trials Organization (PRINTO) has begun collecting data for the EPidemiology, treatment, and Outcomes of Childhood Arthritis (EPOCA) study. ${ }^{160}$ This multinational collaboration is focused on characterizing and comparing the frequency of JIA subtypes in different countries and different continents. Additional objectives of the EPOCA study are defining the therapeutic approaches adopted by pediatric rheumatologists practicing in diverse areas and describing the disease and health status of children with JIA currently being followed worldwide.

CARRA is a North American multicenter collaborative effort focused on the prevention and treatment of JIA. ${ }^{161}$ Utilizing shared patient registries to analyze treatment outcomes, this organization has taken patient care beyond that of just characterizing treatment strategies. Since its introduction in 2002, CARRA has generated a number of consensus treatment plans for JIA as a means to standardize therapy. The most recent protocol regarding polyarticular JIA has been outlined in this review article. ${ }^{13}$

In conclusion, most of the knowledge of polyarticular JIA is still evolving. The epidemiology of JIA is highly variable and studies are in progress to better define this disease. Research continues on the genetics and environment to better identify the pathophysiological influences. Treatment has improved greatly with new focus on standardizing treatments based on JIA subtype. In addition, newer agents are proving to be successful and promising for what was once a debilitating disorder.

\section{Disclosure}

The authors report no conflicts of interest in this work. 


\section{References}

1. Petty RE, Southwood TR, Manners P, et al. International League of Associations for Rheumatology classification of juvenile idiopathic arthritis: second revision, Edmonton, 2001. J Rheumatol. 2004;31(2): 390-392.

2. Ravelli A, Martini A. Juvenile idiopathic arthritis. Lancet. 2007;369(9563):767-778.

3. Ringold S, Seidel KD, Koepsell TD, Wallace CA. Inactive disease in polyarticular juvenile idiopathic arthritis: current patterns and associations. Rheumatology (Oxford). 2009;48(8):972-977.

4. European League Against Rheumatism. EULAR Bulletin No 4: Nomenclature and Classification of Arthritis in Children. Basel: National Zeitung AG; 1977.

5. Cassidy JT, Levinson JE, Bass JC, et al. A study of classification criteria for a diagnosis of juvenile rheumatoid arthritis. Arthritis Rheum. 1986;29(2):274-281.

6. Martini A. JIA in 2011: new takes on categorization and treatment. Nat Rev Rheumatol. 2012;8(2):67-68.

7. Ravelli A, Felici E, Magni-Manzoni S, et al. Patients with antinuclear antibody-positive juvenile idiopathic arthritis constitute a homogeneous subgroup irrespective of the course of joint disease. Arthritis Rheum. 2005;52(3):826-832.

8. Ravelli A, Varnier GC, Oliveira S, et al. Antinuclear antibody-positive patients should be grouped as a separate category in the classification of juvenile idiopathic arthritis. Arthritis Rheum. 2011;63(1):267-275.

9. Sailer M, Cabral D, Petty RE, Malleson PN. Rheumatoid factor positive, oligoarticular onset juvenile rheumatoid arthritis. J Rheumatol. 1997;24:586-588.

10. Brunner J, Sitzmann FC. The diagnostic value of anti-cyclic citrullinated peptide (CCP) antibodies in children with juvenile idiopathic arthritis. Clin Exp Rheumatol. 2006;24(4):449-451.

11. Tebo AE, Jaskowski T, Davis KW, et al. Profiling anti-cyclic citrullinated peptide antibodies in patients with juvenile idiopathic arthritis. Pediatr Rheumatol Online J. 2012;10(1):29.

12. Greenwald AG, Zakerzadeh A, Laxer RM, et al. Later-onset rheumatoid factor negative polyarticular juvenile idiopathic arthritis (JIA): a unique patient group? Clin Exp Rheumatol. 2013;31(4):645-652.

13. Ringold S, Weiss PF, Colbert RA, et al. Childhood Arthritis and Rheumatology Research Alliance consensus treatment plans for new onset polyarticular juvenile idiopathic arthritis. Arthritis Care Res (Hoboken). Epub December 10, 2013.

14. Fujikawa S, Okuni M. A nationwide surveillance study of rheumatic diseases among Japanese children. Acta Paediatr Jpn. 1997;39(2): 242-244.

15. Huang JL, Yao TC, See LC. Prevalence of pediatric systemic lupus erythematosus and juvenile chronic arthritis in a Chinese population: a nation-wide prospective population-based study in Taiwan. Clin Exp Rheumatol. 2004;22(6):776-780.

16. Adib N, Hyrich K, Thornton J, et al. Association between duration of symptoms and severity of disease at first presentation to pediatric rheumatology: results from the Childhood Arthritis Prospective Study. Rheumatology (Oxford). 2008;47(7):991-995.

17. Saurenmann RK, Rose, JB, Tyrrell P, et al. Epidemiology of juvenile idiopathic arthritis in a multiethnic cohort: ethnicity as a risk factor. Arthritis Rheum. 2007;56(6):1974-1984.

18. Akhter E, Bilal S, Kiani A, Haque U. Prevalence of arthritis in India and Pakistan: a review. Rheumatol Int. 2011;31(7):849-855.

19. Berntson L, Andersson Gare B, Fasth A, et al. Incidence of juvenile idiopathic arthritis in the Nordic countries. A population based study with special reference to the validity of the ILAR and EULAR criteria J Rheumatol. 2003;30(10):2275-2282.

20. Kaipiainen-Seppanen O, Savolainen A. Changes in the incidence of juvenile rheumatoid arthritis in Finland. Rheumatology (Oxford). 2001;40(8):928-932.

21. Pruunsild C, Uibo K, Liivamagi H, Tarraste S, Talvik T, Pelkonen P. Incidence of juvenile idiopathic arthritis in children in Estonia: a prospective population-based study. Scand J Rheumatol. 2007;36(1) $7-13$.
22. Manners PJ, Diepeveen DA. Prevalence of juvenile chronic arthritis in a population of 12-year-old children in urban Australia. Pediatrics. 1996;98(1):84-90.

23. Von Koskull S, Truckenbrodt H, Holle R, Hormann A. Incidence and prevalence of juvenile arthritis in an urban population of southern Germany: a prospective study. Ann Rheum Dis. 2001;60(10):940-945.

24. Towner SR, Michet CJ Jr, O'Fallon WM, Nelson AM, et al. The epidemiology of juvenile arthritis in Rochester, Minnesota 1960-1979. Arthritis Rheum. 1983;26(10):1208-1213.

25. Modesto C, Anton J, Rodriguez B, et al. Incidence and prevalence of juvenile idiopathic arthritis in Catalonia (Spain). Scand J Rheumatol. 2010;39(6):472-479.

26. Peterson LS, Mason T, Nelson AM, O’Fallon WM, Gabriel SE. Juvenile rheumatoid arthritis in Rochester, Minnesota 1960-1993. Is the epidemiology changing? Arthritis Rheum. 1996;39(8):1385-1390.

27. Solau-Gervais E, Robin C, Gambert C, et al. Prevalence and distribution of juvenile idiopathic arthritis in a region of Western France. Joint Bone Spine. 2010;77(1):47-49.

28. Mielants H, Veys EM, Maertens M, et al. Prevalence of inflammatory rheumatic diseases in an adolescent urban student population, age 12 to 18, in Belgium. Clin Exp Rheumatol. 1993;11(5):563-567.

29. Danner S, Sordet C, Terzic J, et al. Epidemiology of juvenile idiopathic arthritis in Alsace, France. J Rheumatol. 2006;33(7):1377-1381.

30. Arguedas O, Porras O, Fasth A. Juvenile chronic arthritis in Costa Rica. A pilot referral study. Clin Exp Rheumatol. 1995;13(1):119-123.

31. Merino R, De Inocencio J, Garcia-Consuegra J. Evaluation of ILAR classification criteria for juvenile idiopathic arthritis in Spanish children. J Rheumatol. 2001;28(12):2731-2736.

32. Pruunsild C, Uibo K, Liivamagi H, Tarraste S, Talvik T, Pelkonen P. Prevalence and short-term outcomes of juvenile idiopathic arthritis: a population-based study in Estonia. Clin Exp Rheumatol. 2007;25(4): 649-653.

33. Fujikawa S, Okuni M. Clinical analysis of 570 cases with juvenile rheumatoid arthritis: results of a nationwide retrospective survey in Japan. Acta Paediatr Jpn. 1997;39(2):245-249.

34. Krumrey-Langkammerer M, Hafner R. Evaluation of the ILAR criteria for juvenile idiopathic arthritis. J Rheumatol. 2001;28(11)2544-2547.

35. Kunjir V, Venugopalan A, Chopra A. Profile of Indian patients with juvenile onset chronic inflammatory joint disease using the ILAR classification criteria for JIA: a community-based cohort study. J Rheumatol. 2010;37(8):1756-1762.

36. Abou El-Soud AM, El-Najjar AR, El-Shahawy EE, et al. Prevalence of juvenile idiopathic arthritis in Sharkia Governorate, Egypt: epidemiological study. Rheumatol Int. 2013;33(9):2315-2322.

37. Oen K, Fast M, Postl B. Epidemiology of juvenile rheumatoid arthritis in Manitoba, Canada, 1975-92: cycles in incidence. J Rheumatol. 1995;22(4):745-750.

38. Gare BA, Fasth A. Epidemiology of juvenile chronic arthritis in southwestern Sweden: a 5-year prospective population study. Pediatrics. 1992;90(6):950-958.

39. Yilmaz M, Kendirli SG, Altintas DU, Karakoc GB, Inal A, Kilic M. Juvenile idiopathic arthritis profile in Turkish children. Pediatr Int. 2008;50(2):154-158.

40. Weakley K, Esser M, Scott C. Juvenile idiopathic arthritis in two tertiary centers in the Western Cape, South Africa. Pediatr Rheumatol Online J. 2012;10(1):35.

41. Khuffash FA, Majeed HA, Lubani MM, Najdi KN, Gunawardana SS, Bushnarq R. Epidemiology of juvenile chronic arthritis and other connective tissue diseases among children in Kuwait. Ann Trop Paediatr. 1990;10(3):255-259.

42. Chipeta J, Njobvu P, Wa-Somwe S, Chintu C, McGill PE, Bucala R. Clinical patterns of juvenile idiopathic arthritis in Zambia. Pediatr Rheumatol Online J. 2013;11(1):33.

43. Hanova P, Pavelka K, Dostal C, Holcatova I, Pikhart H. Epidemiology of rheumatoid arthritis, juvenile idiopathic arthritis and gout in two regions of the Czech Republic in a descriptive population-based survey in 2002-2003. Clin Exp Rheumatol. 2006;24(5):499-507. 
44. Aggarwal A, Misra R. Juvenile chronic arthritis in India: is it different from that seen in Western countries? Rheumatol Int. 1994;14(2): $53-56$.

45. Adelowo OO, Umar A. Juvenile idiopathic arthritis among Nigerians: a case study. Clin Rheumatol. 2010;29(7):757-761.

46. Nielsen HE, Dorup J, Herlin T, Larsen K, Nielsen S, Pedersen FK. Epidemiology of juvenile chronic arthritis: risk dependent on sibship, parental income, and housing. J Rheumatol. 1999;26(7):1600-1605.

47. Ellis JA, Ponsonby AL, Pezic A, et al. CLARITY - ChiLdhood Arthritis Risk factor Identification sTudY. Pediatr Rheumatol Online J. 2012;10(1):37.

48. Ehrmann Feldman D, Bernatsky S, Houde M. The incidence of juvenile rheumatoid arthritis in Quebec: a population data-based study. Pediatr Rheumatol Online J. 2009;7:20.

49. Bertilsson L, Andersson-Gare B, Fasth A, Petersson IF, ForsbladD'elia H. Disease course, outcome, and predictors of outcome in a population-based juvenile chronic arthritis cohort followed for 17 years. J Rheumatol. 2013;40(5):715-724.

50. Fantini F, Gerloni V, Gattinara M, Cimaz R, Arnoldi C, Lupi E. Remission in juvenile chronic arthritis: a cohort of 683 consecutive cases with a mean 10 year follow-up. J Rheumatol. 2003;30(3):579-584.

51. Oen K, Malleson PN, Cabral DA, Rosenberg AM, Petty RE, Cheang M. Disease course and outcome of juvenile rheumatoid arthritis in a multicenter cohort. J Rheumatol. 2002;29(9):1989-1999.

52. Vidqvist KL, Malin M, Varjolahti-Lehtinen T, Korpela MM. Disease activity of idiopathic juvenile arthritis continues through adolescence despite the use of biologic therapies. Rheumatology (Oxford). 2013;52(11):1999-2003.

53. Flato B, Lien G, Smerdel A, et al. Prognostic factors in juvenile rheumatoid arthritis: a case-control study revealing early predictors and outcome after 14.9 years. J Rheumatol. 2003;30(2):386-393.

54. Beukelman T, Patkar NM, Saag KG, et al. 2011 American College of Rheumatology recommendations for the treatment of juvenile idiopathic arthritis: initiation and safety monitoring of therapeutic agents for the treatment of arthritis and systemic features. Arthritis Care Res (Hoboken). 2011;63(4):465-482.

55. Gilliam BE, Chauhan AK, Low JM, Moore TL. Measurement of biomarkers in juvenile idiopathic arthritis patients and their significant association with disease severity: a comparative study. Clin Exp Rheumatol. 2008;26(3):492-497.

56. Omar A, Abo-Elyoun I, Hussein H, et al. Anti-cyclic citrullinated peptide (anti-CCP) antibody in juvenile idiopathic arthritis (JIA): correlations with disease activity and severity of joint damage (a multicenter trial). Joint Bone Spine. 2013;80(1):38-43.

57. Ruperto N, Ravelli A, Levinson JE, et al. Long-term health outcomes and quality of life in American and Italian inception cohorts of patients with juvenile rheumatoid arthritis. II. Early predictors of outcome. J Rheumatol. 1997;24(5):952-958.

58. Magni-Manzoni S, Rossi F, Pistorio A, et al. Prognostic factors for radiographic progression, radiographic damage, and disability in juvenile idiopathic arthritis. Arthritis Rheum. 2003;48(12):3509-3517.

59. Oen K, Malleson PN, Cabral DA, et al. Early predictors of long-term outcomes in patients with juvenile rheumatoid arthritis: subset-specific correlations. J Rheumatol. 2003;30(3):585-593.

60. Packham JC, Hall MA. Long-term follow-up of 246 adults with juvenile idiopathic arthritis: functional outcome. Rheumatology (Oxford). 2002;41(12):1428-1435.

61. Packham JC, Hall MA, Pimm TJ. Long-term follow-up of 246 adults with juvenile idiopathic arthritis: predictive factors for mood and pain. Rheumatology (Oxford). 2002;41(12):1444-1449.

62. Packham JC, Hall MA. Long-term follow-up of 246 adults with juvenile idiopathic arthritis: education and employment. Rheumatology (Oxford). 2002;41(12):1436-1439.

63. Thomas E, Symmons DPM, Brewster DH, Black RJ, Macfarlane GJ. National study of cause-specific mortality in rheumatoid arthritis, juvenile chronic arthritis, and other rheumatic conditions: a 20 year follow-up study. J Rheumatol. 2003;30(5):958-965.
64. Hinks A, Cobb J, Marion MC, et al. Dense genotyping of immunerelated disease regions identifies 14 new susceptibility loci for juvenile idiopathic arthritis. Nat Genet. 2013;45(6):664-669.

65. Phelan JD, Thompson SD, Glass DN. Susceptibility to JRA/JIA: complementing general autoimmune and arthritis traits. Genes Immun. 2006;7(1):1-10.

66. Moroldo MB, Tague BL, Shear ES, Glass DN, Giannini EH. Juvenile rheumatoid arthritis in affected sibpairs. Arthritis Rheum. 1997;40(11): 1962-1966.

67. Prahalad S, Zeft AS, Pimentel R, et al. Quantification of the familial contribution to juvenile idiopathic arthritis. Arthritis Rheum. 2010;62(8): 2525-2529.

68. Prahalad S, Glass DN. A comprehensive review of the genetics of juvenile idiopathic arthritis. Pediatr Rheumatol Online J. 2008;6:11.

69. Murray KJ, Moroldo MB, Donnelly P, et al. Age-specific effects of juvenile rheumatoid arthritis-associated HLA alleles. Arthritis Rheum. 1999;42(9):1843-1853.

70. Gorman JD, Criswell LA. The shared epitope and severity of rheumatoid arthritis. Rheum Dis Clin North Am. 2002;28(1):59-78.

71. Fernandez-Vina M, Fink CW, Stastny P. HLA associations in juvenile arthritis. Clin Exp Rheumatol. 1994;12(2):205-214.

72. Thomson W, Barrett JH, Donn R, et al. Juvenile idiopathic arthritis classified by the ILAR criteria: HLA associations in UK patients. Rheumatology (Oxford). 2002;41(10):1183-1189.

73. Hallenbach JA, Thompson SD, Bugawan TL, et al. Juvenile idiopathic arthritis and HLA class I and class II interactions and age-at-onset effects. Arthritis Rheum. 2010;62(6):1781-1791.

74. Prahalad S, Ryan MH, Shear ES, Thompson SD, Giannini EH, Glass DN. Juvenile rheumatoid arthritis: linkage to HLA demonstrated by allele sharing in affected sibpairs. Arthritis Rheum. 2000;43(10): 2335-2338.

75. Hinks A, Barton A, John S, et al. Association between the PTPN22 gene and rheumatoid arthritis and juvenile idiopathic arthritis in a UK population: further support that PTPN22 is an autoimmunity gene. Arthritis Rheum. 2005;52(6):1694-1699.

76. Vang T, Congia M, Macis MD, et al. Autoimmune-associated lymphoid tyrosine phosphatase is a gain-of-function variant. Nat Genet. 2005;37(12):1317-1319.

77. Prahalad S, Hansen S, Whiting A, et al. Variants in TNFAIP3, STAT4, and C12orf30 loci associated with multiple autoimmune diseases are also associated with juvenile idiopathic arthritis. Arthritis Rheum. 2009;60(7):2124-2130.

78. Zhao Y, Liu X, Liu X, et al. Association of STAT4 gene polymorphism with increased susceptibility of rheumatoid arthritis in a northern Chinese Han subpopulation. Rheum Dis. 2013;16(2):178-184.

79. Albers HM, Kurreeman FA, Houwing-Duistermaat JJ, et al. The TRAF1/C5 region is a risk factor for polyarthritis in juvenile idiopathic arthritis. Ann Rheum Dis. 2008;67(11):1578-1580.

80. Schmeling H, Wagner U, Peterson A, Horneff G. Tumor necrosis factor alpha promoter polymorphisms in patients with juvenile idiopathic arthritis. Clin Exp Rheumatol. 2006;24(1):103-108.

81. Hinks A, Cobb J, Sudman M, et al. Investigation of rheumatoid arthritis susceptibility loci in juvenile idiopathic arthritis confirms high degree of overlap. Ann Rheum Dis. 2012;71(7):1117-1121.

82. Thompson SD, Sudman M, Ramos PS, et al. The susceptibility loci juvenile idiopathic arthritis shares with other autoimmune diseases extend to PTPN2, COG6, and ANGPT1. Arthritis Rheum. 2010;62(11):3265-3276.

83. M'Rabet L, Vos AP, Boehm G, Garssen J. Breast-feeding and its role in early development of the immune system in infants: consequences for health later in life. J Nutr. 2008;138(9):1782S-1790S.

84. Mason T, Rabinovich CE, Fredrickson DD, et al. Breast-feeding and the development of juvenile rheumatoid arthritis. $J$ Rheumatol. 1995;22(6):1166-1170.

85. Rosenberg AM. Evaluation of associations between breast feeding and subsequent development of juvenile rheumatoid arthritis. J Rheumatol. 1996;23(6):1080-1082. 
86. Young KA, Parrish LA, Zerbe GO, et al. Perinatal and early childhood risk factors associated with rheumatoid factor positivity in a healthy pediatric population. Ann Rheum Dis. 2007;66(2):179-183.

87. Jacobsson LT, Jacobsson ME, Askling J, Knowler WC. Perinatal characteristics and risk of rheumatoid arthritis. BMJ. 2003;326(7398): 1068-1069.

88. Sugiyama D, Nishimura K, Tamaki K, et al. Impact of smoking as a risk factor for developing rheumatoid arthritis: a meta-analysis of observational studies. Ann Rheum Dis. 2010;69(1):70-81.

89. Wilson K, Goldsmith $\mathrm{CH}$. Does smoking cause rheumatoid arthritis? J Rheumatol. 1999;26(1):1-3.

90. George J, Levy Y, Schoenfeld Y. Smoking and immunity: an additional player in the mosaic of autoimmunity. Scand J Immunol. 1997;45(1): $1-6$.

91. Jaakkola JJ, Gissler M. Maternal smoking in pregnancy as a determinant of rheumatoid arthritis and other inflammatory polyarthropathies during the first 7 years of life. Int J Epidemiol. 2005;34(3): 664-671.

92. Carlens C, Jacobsson LT, Brandt L, Cnattingius S, Stephansson O, Askling J. Perinatal characteristics, early life infections, and later risk of rheumatoid arthritis and juvenile idiopathic arthritis. Ann Rheum Dis. 2009;68(7):1159-1164.

93. Heisel JS. Life changes as etiologic factors in juvenile rheumatoid arthritis. J Psychosom Res. 1972;16(6):411-420.

94. Meyerowitz S, Jacox RF, Hess DW. Monozygotic twins discordant for rheumatoid arthritis: a genetic, clinical, and psychological study of eight sets. Arthritis Rheum. 1968;11(1):1-21.

95. Henoch MJ, Batson JW, Baum J. Psychosocial factors in juvenile rheumatoid arthritis. Arthritis Rheum. 1978;21(2):229-233.

96. Neufeld KM, Karunanayake CP, Maenz LY, Rosenberg AM. Stressful life events antedating chronic childhood arthritis. $J$ Rheumatol. 2013;40(10):1756-1765.

97. Vandvik IH, Hoyeraal HM, Fagertun H. Chronic family difficulties and stressful life events in recent onset juvenile arthritis. J Rheumatol. 1989;16(8):1088-1092.

98. Slopen N, Kubzansky LD, McLaughlin KA, Koenen KC. Childhood adversity and inflammatory processes in youth: a prospective study. Psychoneuroendocrinology. 2013;38(2):188-200.

99. Roupe van der Voort C, Heijnen CJ, Wulffraat N, Kuis W, Kavelaars A. Stress induces increases in IL-6 production by leucocytes of patients with the chronic inflammatory disease juvenile rheumatoid arthritis: a putative role for $\alpha_{1}$-adrenergic receptors. J Neuroimmunol. 2000;110(1-2):223-229.

100. Franssila R, Hedman K. Infection and musculoskeletal conditions: viral causes of arthritis. Best Pract Res Clin Rheumatol. 2006;20(6): 1139-1157.

101. Kivity S, Arango MT, Ehrenfeld M, et al. Infection and autoimmunity in Sjogren's syndrome: a clinical study and comprehensive review. J Autoimmun. 2014;51:17-22.

102. Shoenfeld Y, Zandman-Goddard G, Stojanovich L, et al. The mosaic of autoimmunity: hormonal and environmental factors involved in autoimmune diseases - 2008. Isr Med Assoc J. 2008;10(1):8-12.

103. Freimanis G, Hooley P, Ejtehadi HD, et al. A role for human endogenous retrovirus-K (HML-2) in rheumatoid arthritis: investigating mechanisms of pathogenesis. Clin Exp Immunol. 2010;160(3):340-347.

104. Pritchard MH, Matthews N, Munro J. Antibodies to influenza A in a cluster of children with juvenile chronic arthritis. Br J Rheumatol. 1988;27(3):176-180.

105. Chantler JK, Tingle AJ, Petty RE. Persistent rubella virus infection associated with chronic arthritis in children. $N$ Engl J Med. 1985;313(18):1117-1123.

106. Gonzalez B, Larranga C, Leon O, et al. Parvovirus B19 may have a role in the pathogenesis of juvenile idiopathic arthritis. J Rheumatol. 2007;34(6):1336-1340.

107. Aghighi Y, Gilani Sh M, Razavi M, Zamani A, Daneshjoo K. Juvenile rheumatoid arthritis in children with Ebstein Barr virus infection. Pak J Biol Sci. 2007;10(20):3638-3643.
108. Hokynar K, Brunstein J, Soderlund-Venermo M, et al. Integrity and full coding sequence of B19 virus DNA persisting in human synovial tissue. J Gen Virol. 2000;81(Pt 4):1017-1025.

109. Zulian F, Martini G, Gobber D, Plebani M, Zacchello F, Manners P. Triamcinolone acetonide and hexacetonide intra-articular treatment of symmetrical joints in juvenile idiopathic arthritis: a double-blind trial. Rheumatology (Oxford). 2004;43(10):1288-1291.

110. Wallace CA, Giannini EH, Spalding SJ, et al. Trial of early aggressive therapy in polyarticular juvenile idiopathic arthritis. Arthritis Rheum. 2012;64(6):2012-2021.

111. Giannini E, Ruperto N, Ravelli A, Lovell DJ, Felson DT, Martini A. Preliminary definition of improvement in juvenile arthritis. Arthritis Rheum. 1997;40(7):1202-1209.

112. Ilowite NT, Laxer RM. Pharmacology and drug therapy. In: Cassidy JT, Petty RE, Laxer RM, Lindsley CB, editors. Textbook of Pediatric Rheumatology. 6th ed. Philadelphia, PA: Saunders Elsevier; 2011:71-126.

113. Giannini EH, Brewer EJ, Kuzmina N, et al. Methotrexate in resistant juvenile rheumatoid arthritis: results of the USA-USSR double-blind, placebo-controlled trial. N Engl J Med. 1992; 326(16):1043-1049.

114. Woo P, Southwood TR, Prieur AM, et al. Randomized, placebocontrolled, crossover trial of low-dose oral methotrexate in children with extended oligoarticular or systemic arthritis. Arthritis Rheum. 2000;43(8):1849-1857.

115. Klein A, Kaul I, Foeldvari I, Ganser G, Urban A, Horneff G. Efficacy and safety of oral and parenteral methotrexate therapy in children with juvenile idiopathic arthritis: an observational study with patients from the German Methotrexate Registry. Arthritis Care Res (Hoboken) 2012;64(9):1349-1356.

116. Silverman E, Mouy R, Spiegel L, et al. Leflunomide or methotrexate for juvenile rheumatoid arthritis. $N$ Engl J Med. 2005;352(16): 1655-1666.

117. Silverman E, Spiegel L, Hawkins D, et al. Long-term open-label preliminary study of the safety and efficacy of leflunomide in patients with polyarticular-course juvenile rheumatoid arthritis. Arthritis Rheum. 2005;52(2):554-562.

118. Van Rossum MA, Fiselier TJ, Franssen MJ, et al. Sulfasalazine in the treatment of juvenile chronic arthritis: a randomized, double-blind, placebocontrolled multicenter study. Arthritis Rheum. 1998;41(5): 808-816.

119. Savolainen HA, Kautiainen H, Isomaki H, Aho, K, Verronen P. Azathioprine in patients with juvenile chronic arthritis: a long-term follow-up study. J Rheumatol. 1997;24(12):2444-2450.

120. Ruperto N, Ravelli A, Castell E, et al. Cyclosporine A in juvenile idiopathic arthritis. Results of the PRCSG/PRINTO Phase IV post marketing surveillance study. Clin Exp Rheumatol. 2006;24(5):599-605.

121. Brewer EJ, Giannini EH, Kuzmina N, Alekseev L. Penicillamine and hydroxychloroquine in the treatment of severe juvenile rheumatoid arthritis. Results of the USA-USSR double-blind placebo-controlled trial. N Engl J Med. 1986;314(20):1269-1276.

122. Tanaka H, Tsugawa K, Suzuki K, et al. Treatment of difficult cases of systemic-onset juvenile idiopathic arthritis with tacrolimus. Eur J Pediatr. 2007;166(10):1053-1055

123. Lehman TJ, Schechter SJ, Sundel RP, Oliveira SK, Huttenlocher A, Onel KB. Thalidomide for severe systemic onset juvenile rheumatoid arthritis: a multicenter study. J Pediatr. 2004;145(6):856-857.

124. O'Dell JR, Mikuls TR, Taylor TH, et al. Therapies for active rheumatoid arthritis after methotrexate failure. $N$ Engl J Med. 2013;369(4):307-318.

125. Lovell DJ, Giannini EH, Reiff A, et al. Etanercept in children with polyarticular juvenile rheumatoid arthritis. $N$ Engl $\mathrm{J} \mathrm{Med}$. 2000;342(11):763-769.

126. Tynjala P, Vahasalo P, Tarkiainen M, et al. Aggressive combination drug therapy in very early polyarticular juvenile idiopathic arthritis (ACUTE-JIA): a multicenter randomized open-label clinical trial. Ann Rheum Dis. 2011;70(9):1605-1612. 
127. Otten MH, Prince FH, Armbrust W, et al. Factors associated with treatment response to etanercept in juvenile idiopathic arthritis. JAMA. 2011;306(21):2340-2347.

128. Ruperto N, Lovell DJ, Cuttica R, et al. A randomized, placebocontrolled trial of infliximab plus methotrexate for the treatment of polyarticular-course juvenile rheumatoid arthritis. Arthritis Rheum. 2007;56(9):3096-3106.

129. Lovell DJ, Ruperto N, Goodman S, et al. Adalimumab with or without methotrexate in juvenile rheumatoid arthritis. $N$ Engl J Med. 2008;359(8):810-820.

130. Ruperto N, Lovell DJ, Quartier P, et al. Abatacept in children with juvenile idiopathic arthritis: a randomized, double-blind, placebocontrolled withdrawal trial. Lancet. 2008;372(9636):383-391.

131. Ruperto N, Lovell DJ, Li T, et al. Abatacept improves health-related quality of life, pain, sleep quality, and daily participation in subjects with juvenile idiopathic arthritis. Arthritis Care Res (Hoboken). 2010;62(11):1542-1551.

132. Yokota S, Imagawa T, Mori M, et al. Efficacy and safety of tocilizumab in patients with systemic-onset juvenile idiopathic arthritis: a randomized, double-blind, placebo-controlled, withdrawal Phase III trial. Lancet. 2008;371(9617):998-1006.

133. De Benedetti F, Brunner HI, Ruperto N, et al. Randomized trial of tocilizumab in systemic juvenile idiopathic arthritis. $N$ Engl J Med. 2012;367(25):2385-2395.

134. Brunner H, Ruperto N, Zuber Z, et al. Efficacy and safety of tocilizumab in patients with polyarticular juvenile idiopathic arthritis: data from a Phase III trial [abstract]. Arthritis Rheum. 2012; 64(Suppl 10):S682.

135. Brunner HI, Ruperto N, Zuber Z, et al. Efficacy and safety of tocilizumab in patients with polyarticular-course juvenile idiopathic arthritis: 2-year data from CHERISH [abstract]. Arthritis Rheumatol. 2014;66(Suppl 11):S5-S6.

136. Alexeeva EI, Valieva SI, Bzarova TM, et al. Efficacy and safety of repeat courses of rituximab treatment in patients with severe refractory juvenile idiopathic arthritis. Clin Rheumatol. 2011;30(9): 1163-1172.

137. Giannini EH, Lovell DJ, Silverman ED, Sundel RP, Tague BL, Ruperto N. Intravenous immunoglobulin in the treatment of polyarticular juvenile rheumatoid arthritis: a Phase I/II study. J Rheumatol. 1996;23(5): 919-924.

138. Cohen S, Hurd E, Cush J, et al. Treatment of rheumatoid arthritis with anakinra, a recombinant human interleukin-1 receptor antagonist, in combination with methotrexate: results of a 24-week multicenter, randomized, double-blind, placebo-controlled trial. Arthritis Rheum. 2002;46(3):614-624.

139. Ilowite N, Porras O, Reiff A, et al. Anakinra in the treatment of polyarticular-course juvenile rheumatoid arthritis: safety and preliminary efficacy results of a randomized multicenter study. Clin Rheumatol. 2009;28(2):129-137.

140. Quartier P, Allantaz F, Cimaz R, et al. A multicenter, randomized, double-blind, placebo-controlled trial with the interleukin-1 receptor antagonist anakinra in patients with systemic-onset juvenile idiopathic arthritis (ANAJIS trial). Ann Rheum Dis. 2011;70(5):747-754.

141. Nigrovic PA, Mannion M, Prince FH, et al. Anakinra as first-line disease-modifying therapy in systemic juvenile idiopathic arthritis: report of 46 patients from an international multicenter study. Arthritis Rheum. 2011;63(2):545-555.

142. Ruperto N, Brunner HI, Quartier P, et al. Two randomized trials of canakinumab in systemic juvenile idiopathic arthritis. $N$ Engl J Med. 2012;367(25):2396-2406.

143. Lovell DJ, Giannini EH, Kimura Y, et al. Long-term safety and efficacy of rilonacept in patients with systemic juvenile idiopathic arthritis. Arthritis Rheum. 2013;65(9):2486-2496.

144. Ringold S, Weiss PF, Beukelman T, et al. 2013 update of the 2011 American College of Rheumatology recommendations for the treatment of juvenile idiopathic arthritis: recommendations for the medical therapy of children with systemic juvenile idiopathic arthritis and tuberculosis screening among children receiving biologic medications. Arthritis Rheum. 2013;65(10):2499-2512.
145. Ruiz Garcia V, Jobanputra P, Burls A, et al. Certolizumab pegol (CDP870) for rheumatoid arthritis in adults [review]. Cochrane Database Syst Rev. 2011;2:CD007649.

146. Singh JA, Noorbaloochi S, Singh G. Golimumab for rheumatoid arthritis: a systematic review. J Rheumatol. 2010;37(6):1096-1104.

147. UCB Biosciences GmbH. Pediatric arthritis study of certolizumab pegol (PASCAL). Available from: http://clinicaltrials.gov/ct2/show/ NCT01550003. NLM identifier: NCT01550003. Accessed June 27, 2014.

148. Brunner H, Ruperto N, Tzaribachev N, et al. A multi-center, doubleblind, randomized-withdrawal trial of subcutaneous golimumab in pediatric patients with active polyarticular course juvenile idiopathic arthritis despite methotrexate therapy: week 48 results [abstract]. Arthritis Rheumatol. 2014;66(Suppl 11):S191-S192.

149. Tzaribachev N, Tzaribachev C, Mehrwald M, Koos B. GO-Kids imaging substudy: MRI treatment response to $30 \mathrm{mg} / \mathrm{m}^{2}$ 4-weekly subcutaneous injections of golimumab in children with polyarticular JIA - preliminary results of the open label portion [abstract]. Arthritis Rheum. 2013;65(Suppl 10):S118.

150. Fleischmann R, Kremer J, Cush J, et al. Placebo-controlled trial of tofacitinib monotherapy in rheumatoid arthritis. $N$ Engl J Med. 2012;367(6):495-507.

151. Pfizer. Long-term safety study of CP-690,550 in patients with juvenile idiopathic arthritis. Available from: http://clinicaltrials.gov/ct2/show/ NCT01500551. NLM identifier: NCT01500551. Accessed June 27, 2014.

152. Galien R, Vayssiere B, de Vos S, et al. Analysis of the JAK1 selectivity of GLPG0634 and its main metabolite in different species, healthy volunteers, and rheumatoid arthritis patients [abstract]. Arthritis Rheum. 2013;65(Suppl 10):S209-S210.

153. Galapagos NV. Long-term follow-up study of GLPG0634 in active rheumatoid arthritis patients (DARWIN3). Available from: http/:clinicaltrials.gov/show/NCT02065700. NLM identifier: NCT02065700. Accessed June 27, 2014.

154. Vojinovic J, Damjanov N, D'Urzo C, et al. Safety and efficacy of an oral histone deacetylase inhibitor in systemic-onset juvenile idiopathic arthritis. Arthritis Rheum. 2011;63(5):1452-1458.

155. Vojinovic J, Damjanov N. HDAC inhibition in rheumatoid arthritis and juvenile idiopathic arthritis. Mol Med. 2011;17(5-6): 397-403.

156. Tak PP, Balanescu A, Tseluyko V, et al. Chemokine receptor CCR1 antagonist CCX354-C treatment for rheumatoid arthritis: CARAT2, a randomized, placebo controlled clinical trial. Ann Rheum Dis. 2013;72(3):337-344.

157. Dawes P, Dimic A, Genovese MC, et al. Oskira-2: a Phase III, multicenter, randomized, double-blind, placebo-controlled parallel-group study of two dosing regimens of fostamatinib in rheumatoid arthritis patients with an inadequate response to disease-modifying antirheumatic drugs [abstract]. Arthritis Rheum. 2013;65(Suppl 10): S198-S199.

158. Genovese M, van der Heijde D, Keystone E, et al. Oskira-3: a Phase III, multicenter, randomized, double-blind, placebo-controlled parallelgroup study of two dosing regimens of fostamatinib in rheumatoid arthritis patients with an inadequate response to a tumor necrosis factor- $\alpha$ antagonist [abstract]. Arthritis Rheum. 2013;65(Suppl 10): S199-S200.

159. Genovese MC, Carlier H, Erickson J, Braun D, Banerjee S. Results of 64 weeks of treatment with an anti-IL-17 antibody, ixekizumab, in patients with rheumatoid arthritis in a Phase II study [abstract]. Arthritis Rheum. 2013;65(Suppl 10):S188.

160. Consolaro A, Ruperto N, Filocamo G, et al. Seeking insights into the EPidemiology, treatment and Outcome of Childhood Arthritis through a multinational collaborative effort: introduction of the EPOCA study. Pediatr Rheumatol Online J. 2012;10(1):39.

161. Ota S, Cron RQ, Schanberg LE, et al. Research priorities in pediatric rheumatology: the Childhood Arthritis and Rheumatology Research Alliance (CARRA) consensus. Pediatric Rheumatol Online J. $2008 ; 6: 5$. 
Clinical Epidemiology

\section{Publish your work in this journal}

Clinical Epidemiology is an international, peer-reviewed, open access journal focusing on disease and drug epidemiology, identification of risk factors and screening procedures to develop optimal preventative initiatives and programs. Specific topics include: diagnosis, prognosis, treatment, screening, prevention, risk factor modification, systematic

Submit your manuscript here: http://www.dovepress.com/clinical-epidemiology-journal

reviews, risk \& safety of medical interventions, epidemiology \& biostatical methods, evaluation of guidelines, translational medicine, health policies \& economic evaluations. The manuscript management system is completely online and includes a very quick and fair peer-review system, which is all easy to use. 